\title{
INSTRUCTIONS FOR CONTRIBUTORS
}

\section{Editorial Policy}

The journal welcomes high quality contributions on topics closely related to dynamical systems and ergodic theory. Submissions in the field of differential geometry, number theory, operator algebra, differential, topological, symbolic, measurable dynamics and celestial and statistical mechanics are especially welcome. Expository survey papers and reviews of relevant books will be published from time to time.

\section{Submission of manuscripts}

Manuscripts should be submitted via the website: http://mc.manuscriptcentral.com/etds.

Submission of a paper is taken to imply that it has not been previously published and that it is not being considered for publication elsewhere. Authors of articles published in the journal assign copyright to Cambridge University Press (with certain rights reserved) and you will receive a copyright assignment form for signature on acceptance of your paper.

The journal strongly recommends submission of accepted papers in $\mathrm{LT}_{\mathrm{E}} \mathrm{X}$ using the ETDS LATEX class file. Papers that use this class file will be processed more efficiently. A $\mathrm{LTT}_{\mathrm{E}} \mathrm{X} 2 \mathrm{e}$ file etds.cls is available via anonymous ftp from the Cambridge University Press site at ftp.cup.cam.ac.uk in the directory /pub/texarchive/journals/latex/etds-cls/. In case of difficulties with these files, please contact etds@sunrise-setting.co.uk or the Journal editorial office at etds@maths.warwick.ac.uk. Alternatively, authors may use ‘article’ style.

On acceptance of a paper, authors should upload the $\mathrm{LT}_{\mathrm{E}} \mathrm{X}$ source code including the figures (line figures only) and all author-defined macro and style files, together with a pdf produced using the same file, via the submission site http://mc.manuscriptcentral.com/etds.

The publisher reserves the right to typeset any article by conventional means if the author's $\mathrm{T}_{\mathrm{E}} \mathrm{X}$ code presents problems in production.

\section{Manuscript}

Papers should be typed with generous margins. The pages must be numbered.

The first page should give the title, the author's name and institution, and a short abstract intelligible to mathematicians.

The title, while brief, must be informative (e.g. 'A new proof of the ergodic theorem', whereas 'Some applications of a theorem of Birkhoff' would be useless).

\section{Notation}

Avoid abbreviations such as Thm, Prop., Eq., iff. In the text do not use symbols $\forall, \exists, \Rightarrow$ and $\Leftrightarrow$. Fractions are generally best expressed by a solidus. Complicated exponents like $\exp \left\{z^{2} \sin \theta /\left(1+y^{2}\right)\right\}$ should be shown in this and no other way.

It helps if displayed equations or statements which will be quoted later are numbered in order on the right of their line. They can then be referred to by, for example, 'from (7)'.

If an author wishes to mark the end of the proof of a theorem, the sign $\square$ may be used.

Footnotes should be avoided.

\section{Figures}

Graphics should be prepared to professional standards, preferably using Postscript or LATEX drawing facilities. Each text figure must be numbered as Figure 1, Figure 2, .. and its intended position clearly indicated in the manuscript. Figures should be used sparingly and only when they greatly clarify the exposition. The preferred resolutions for submission of electronic artwork are: halftone images 300 dpi; line tone 600 dpi; bitmap 1200 dpi.

Tables

Tables should be numbered (above the table) as Table 1, Table 2, ... Indicate the position of each in the text as for figures.

\section{References}

References should be collected at the end of the paper numbered in alphabetical order of the author's names or by order of citation. Include in the list of references only those works that are cited. For the style of references please consult recent issues of the journal. A reference to a book should give the title, in italics, and then in roman type the publisher's name and the place and year of publication: [4] N. Dunford and J. T. Schwartz. Linear Operators. Part I. Wiley, New York, 1958.

A reference to a paper should give in italics the title of the periodical, the number of the volume and year, and the beginning and end pages of the paper. Journal titles should be abbreviated as in Mathematical Reviews:

[6] J. E. Littlewood. The 'pits effect' for functions in the unit circle. J. Analyse Math. 23 (1970), 236-268.

\section{Proofs}

Authors receive one pdf proof for correction. Typographical and minor corrections only are permitted at this stage. For papers with more than one author the proofs are sent to the first named author unless the editor receives other instructions. It is important that proofs are corrected and returned promptly.

This journal issue has been printed on FSC-certified paper and cover board. FSC is an independent, non-governmental, not-for-profit organization established to promote the responsible management of the world's forests. Please see www.fsc.org for information.

(C) Cambridge University Press 2019 


\title{
Ergodic theory and dynamical systems
}

\author{
VOLUME 40 PART 1 JANUARY 2020
}

\section{CONTENTS}

Hindman, N. A history of central sets (Survey)

Bönicke, C. and Li, K. Ideal structure and pure infiniteness of ample groupoid $C^{*}$-algebras

Catsigeras, E., Guiraud, P. and Meyroneinc, A. Complexity of injective piecewise contracting interval maps

Cui, W. Lebesgue measure of escaping sets of entire functions

Damjanović, D. and $X u, D$. Diffeomorphism group valued cocycles over higher-rank abelian Anosov actions

Dolgopyat, D. and Nándori, P. On mixing and the local central limit theorem for hyperbolic flows

Einsiedler, M. and Maier, A. Simultaneous equidistributing and non-dense points for non-commuting toral automorphisms

Farkas, Á. Interval projections of self-similar sets

Himeki, Y. and Ishii, Y. $\mathcal{M}_{4}$ is regular-closed

Kombrink, S. and Winter, S. Lattice self-similar sets on the real line are not Minkowski measurable

Liao, G., Sun, W., Vargas, E. and Wang, S. Approximation of Bernoulli measures for non-uniformly hyperbolic systems

Salerno, A. and Silverman, J. H. Integrality properties of Böttcher coordinates for one-dimensional superattracting germs

Ueki, J. p-adic Mahler measure and $\mathbb{Z}$-covers of links

\section{Cambridge Core}

For further information about this journal please go to the journal website at: cambridge.org/ets
CAMBRIDGE
UNIVERSITY PRESS 